\title{
Campylobacter jejuni isolations from Mexican and Swedish patients, with repeated symptomatic and/or asymptomatic diarrhoea episodes
}

\author{
E. SJÖGREN, ${ }^{1}$ G. RUIZ-PALACIOS ${ }^{2}$ AND B. KAIJSER ${ }^{1}$ \\ ${ }^{1}$ Department of Clinical Bacteriology, Institute of Clinical Bacteriology, \\ Immunology and Virology, University of Göteborg, Göteborg, Sweden and ${ }^{2}$ Instituto \\ Nacional de la Nutrición, Mexico City, Mexico
}

(Accepted 15 August 1988)

\begin{abstract}
SUMMARY
The presence of different Campylobacter jejuni serotypes in Swedish patients with diarrhoea and in Mexican patients with or without diarrhoea was investigated with special reference to repeated isolations during the course of infection and to symptomatic and asymptomatic episodes. The study included 136 C.jejuni isolates from 62 Mexican children and 173 isolates from 68 Swedish patients. The bacteria were serotyped for heat-stable (HS) and heat-labile (HL) antigen.

Swedish patients, all with symptoms, were in general only infected with one serotype and were rarely reinfected. Mexican patients on the other hand were in general infected with mixed serotypes and frequently reinfected without symptoms with new, different serotypes, a finding which is in concordance with a theory of an induced immunity to surface antigens.
\end{abstract}

\section{INTRODLCTION}

Campylobacter jejuni is an important case of acute diarrhoeal disease occurring in both sporadic and epidemic form (Blaser et al. 1983; Svedhem \& Kaijser, 1980; Skirrow, 1987 ; Jones et al. 1981). Repeated enteric infection with this organism is particularly prevalent in children in developing countries where most of the cases occurring in children over 2 years old are asymptomatic (Glass et al. 1983; Calva et al. 1988; Mathan et al. 1984; Georges-Courbot et al. 1986; Alabi et al. 1986). It has been claimed that different strains appear in the repeated infections, but that a limited number of serotypes dominate (Blaser et al. 1986; Karmali et al. 1983).

Several different factors possibly associated with virulence have been suggested for thermophilic campylobacter such as motility, invasiveness, adhesiveness, enterotoxin and/or cytotoxin production (Guerrant et al. 1987; Klipstein \& Engert, 1984; Johnson \& Lior, 1986; Newell \& McBride, 1985; McSweegan \& Walker, 1986). Klipstein et al. (1985) found a strong correlation between the clinical outcome in the infected host and certain properties of the infecting strain of $C$. jejuni. In our recent study from Sweden, we concluded that there was no 
correlation between the nature and severity of clinical signs and the presence of a specific serotype (Kaijser \& Sjögren, 1985).

The purpose of this investigation was to study the presence of different $C$.jejuni serotypes in patients in Sweden and Mexico with special reference to repeated isolations during the course of infection and also to compare symptomatic and asymptomatic episodes.

\section{MATERIALS AND METHODS}

Bacteria. The study included 136 C.jejuni isolates from 62 Mexican children and 173 isolates from 68 Swedish patients.

Stool specimens were collected by rectal swabs and were cultivated for Campylobacter sp. as described earlier (Sjögren et al. 1987; Calva et al. 1988). Briefly, samples from the Swedish patients were transported in MSM (modified Stuart medium) or SMTM medium (semisolid motility test medium) (Sjögren et al. 1987). The latter were also used as an enrichment medium. All samples were plated directly within $24 \mathrm{~h}$ of sampling and again after $24-48 \mathrm{~h}$ of enrichment. The culture media contained Colombia agar (BBL), horse blood and the selective antibiotics vancomycin, polymyxin $B$ and trimethoprim. Identification of Campylobacter sp. was as described by Skirrow (1977). C. jejuni and C. coli were not differentiated. Local experience shows that $90 \%$ of the strains were $C$. jejuni.

The samples from the Mexican patients were examined by standard procedures with Campy-Bap medium (BBL) made with Brucella agar, lysed sheep erythrocytes and with the selective antibiotics vancomycin, trimethoprim, polymyxin B, amphotericin and cephalothin (Calva et al. 1988).

Strains were stored by lyophilization of a streak from the whole primary, swarming culture.

Serotyping. All serotyping of the Swedish as well as the Mexican strains was performed by the same person at the Department of Clinical Bacteriology, University of Göteborg, Göteborg, Sweden. Upon subcultivation of the lyophilized strains, all morphologically different colonies were serotyped separately if possible. However many of the cultures appeared as morphologically homologous swarming growth.

Serotyping of the heat-stable HS antigen was performed according to the procedure described by Penner et al. (1983) using the indirect haemagglutination technique. The heat-labile HL antigen was determined by the method of Lior et al. (1982) using live bacterial cells suspended in buffered PBS-saline and adsorbed antisera to remove antibodies against homologous heat-stable and heterologous heat-labile antigens.

The hyperimmune antisera used for both groups were produced with reference strains from Drs Penner and Lior and were kindly supplied by the Culture Collection, University of Göteborg (CCUG). Twenty-three HS and 20 different antisera were used based on the typing results with the strains in our recent study (75-95\%) (Kaijser \& Sjögren, 1985) and experience from other epidemiological studies (Skirrow, 1987; Patton et al. 1985). To avoid rough strains or transient antigens, the isolates were subcultivated and retested five times before being recorded as a non-typable strain for the antisera used in the two systems. 
Table 1. Campylobacter isolates from Swedish patients with symptoms of infection (The patients illustrated in the table were selected because they had two or more specimens collected with at least one week intervals between.)

\begin{tabular}{|c|c|c|c|c|c|c|}
\hline \multirow[b]{2}{*}{ Patients } & \multirow[b]{2}{*}{ Initial } & \multicolumn{5}{|c|}{ Sampling period (weeks) } \\
\hline & & 1 & 2 & 3 & 4 & $5-8$ \\
\hline 1 & $2: 4^{*}$ & $2: 4$ & - & - & - & \\
\hline 2 & $\mathrm{NT}: 1^{* *}$ & - & - & 16.9 & - & - \\
\hline 3 & $6: 9$ & - & - & $\ldots$ & 6.9 & - \\
\hline 4 & $15: 2$ & - & - & - & - & $15: 2$ \\
\hline 5 & $3: 2$ & - & $3: 2$ & - & $3: 2$ & - \\
\hline 6 & $2: 4$ & - & - & - & $2: 4$ & - \\
\hline 7 & $2: 4$ & - & - & - & - & $2: 4$ \\
\hline 8 & $2: 4$ & - & $2: 4$ & - & - & - \\
\hline 9 & $8: 7$ & $8: 7$ & - & - & - & - \\
\hline 10 & $6: 4$ & $6: 4$ & - & - & - & - \\
\hline 11 & $4: 1$ & $4: 1$ & - & - & - & - \\
\hline 12 & $1: 1$ & $1: 1$ & - & - & - & - \\
\hline 13 & $5: 2$ & $5: 2$ & - & - & - & - \\
\hline 14 & $2: 4$ & $2: 4$ & - & $\ldots$ & - & - \\
\hline 15 & $2: 4$ & $2: 4$ & - & $2: 4$ & - & - \\
\hline 16 & NT: 4 & NT: $\mathbf{4}$ & - & NT: 4 & - & - \\
\hline 17 & $4: 4$ & - & - & - & - & $8: 16$ \\
\hline 18 & $16: 4$ & $16: 4$ & - & - & - & - \\
\hline 19 & $2: 4$ & - & - & - & $2: 4$ & - \\
\hline 20 & $1: 1$ & - & - & - & $1: 1$ & - \\
\hline 21 & $2: 19$ & - & $2: 19$ & - & - & $2: 19$ \\
\hline 22 & $37: 2$ & $37: 2$ & - & - & - & - \\
\hline 23 & $1: 2$ & $1: 2$ & - & - & - & - \\
\hline 24 & $1: 2$ & - & - & - & - & $1: 2$ \\
\hline 25 & $4: 9$ & - & - & - & - & $13: 11$ \\
\hline 26 & $8: 2$ & - & - & - & $8: 2$ & - \\
\hline 27 & NT $: 2$ & $\ldots$ & - & NT: 2 & - & - \\
\hline 28 & $10: 2$ & - & - & $10: 2$ & - & - \\
\hline 28 & $8: 4$ & $8: 4$ & - & - & - & - \\
\hline
\end{tabular}

*, HS: HL (Heat stable: Heat labile) serotype.

**, NT, not typable strains using our antisera.

Patients. The Mexican children $(n=62)$, all under 4 years of age, were from selected families living in a poor urban community. Weekly stool specimens were obtained over the 12-month study period in 19856 . The campylobacter infection was said to be asymptomatic when there were at least 5 consecutive symptom-free days before and after the isolation of campylobacter in faeces. A symptomatic episode for the Mexican group defined as a diarrhoeal episode occurring within 5 days, before or after, of the faecal isolation of campylobacter.

The Swedish strains were isolated over a period of one year (1985-6) from 68 patients all of whom were aged 15 or more and were seeking medical care for diarrhoea at the Department of Infectious Diseases, Ostra Hospital, Göteborg, Sweden. Rectal swab specimens were collected weekly during the 2-month followup period after the initial diarrhoeal episode. Symptomatic infection for the Swedish patients was recorded when the patient reported that he had had 
Table 2. Campylobacter strains $(n=31)$ from Mexican children with symptoms, serotyped according to the heat-stable HS-antigen and the heat-labile HL-antigen

$\begin{array}{cccccc}\begin{array}{c}\text { Serotype } \\ \text { (HS)** }\end{array} & \begin{array}{c}\text { No. of } \\ \text { strains }\end{array} & \begin{array}{c}\text { Frequency } \\ (\%)\end{array} & \begin{array}{c}\text { Serotype } \\ (\text { HL) })^{* * *}\end{array} & \begin{array}{c}\text { No. of } \\ \text { strains }\end{array} & \begin{array}{c}\text { Frequency } \\ (\%)\end{array} \\ 37 & 4 & 12 \cdot 9 * & 21 & 10 & 32 \cdot 2 \\ 15 & 3 & 9 \cdot 7 & 2 & 8 & 25 \cdot 8 \\ 1 & 3 & 9 \cdot 7 & 36 & 5 & 16 \cdot 1 \\ 8 & 3 & 9 \cdot 7 & 4 & 2 & 6 \cdot 5 \\ 4 & 2 & 6 \cdot 5 & 11 & 2 & 6 \cdot 5 \\ 5 & 1 & 3 \cdot 2 & 13 & 1 & 3 \cdot 2 \\ 6 & 1 & 3 \cdot 2 & 1 & 1 & 3 \cdot 2 \\ 18 & 1 & 3 \cdot 2 & 20 & 1 & 3 \cdot 2 \\ 23 & 1 & 3 \cdot 2 & 12 & 1 & 3 \cdot 2 \\ \text { Total typable } & 19 & 61 \cdot 3 & & 31 & 100 \cdot 0 \\ \text { Not typable } & 12 & 38 \cdot 7 & & 0 & 100 \cdot 0\end{array}$

$* P<0.05$ compared to strains from patients without symptoms. (Table 3 ).

** Hyperimmune antisera against 'reference strains with HS antigens $2,3.9 .10,11,13.14$. $16,17,19,20,21,22$ and 25 were also tested, but none of the strains belonged to any of these serotypes.

*** Hyperimmune antisera against reference strains with HL antigens $5,6,7,8,9,10,16.17$. 18,19 and 22 were also tested, but none of the strains belonged to any of these serotypes.

diarrhoea and when campylobacter was isolated from the stool sample. Two or more specimens were collected during the acute phase of the episode within the first week. In 29 of the 68 patients the interval between the first specimens and the next ones was a week or longer (Table 1).

Statistical calculations. Differences of probabilities were tested by using the Chisquare test with the Yates' correction factor (Colton, 1974).

\section{RESLLTS}

In the Swedish study, most of the patients were infected with one strain regardless of whether the patient was infected in Sweden or abroad. During the whole period of study the patient excreted the same serotype, indicating that no or few reinfections occurred. Table 1 presents the serotypes of the isolates from 29 of the 68 patients from whom samples were collected at intervals greater than one week.

In the Mexican children at the time of the campylobacter isolation, 31 child episodes were diarrhoea-associated (Table 2), while 105 episodes were asymptomatic (Table 3). During the follow-up period $38(61.3 \%)$ of the patients had asymptomatic epidoses only. Six of the patients had both symptomatic and asymptomatic episodes; 1 child had 2 episodes, 1 had 4, 3 had 5 and 1 child had 11 episodes during 1 year. The children were repeatedly infected with new serotypes, and 26 out of the 62 patients $(41.9 \%)$ were infected with mixed Campylobacter sp. at the time of isolation regardless of whether the episodes were symptomatic or asymptomatic. Table 4 illustrates the serotypes found in patients where three or more samples were typed during the 1-year study period. 
Table 3. Campylobacter strains $(n=105)$ from Mexican children without symptoms, serotyped regarding the heat-stable-HS-antigen and the heat-labile-HL-antigen

\begin{tabular}{|c|c|c|c|c|c|}
\hline $\begin{array}{l}\text { Serotype } \\
\text { (HS) }\end{array}$ & $\begin{array}{l}\text { No. of } \\
\text { strains }\end{array}$ & $\begin{array}{c}\text { Frequency } \\
(\%)\end{array}$ & $\begin{array}{l}\text { Serotype } \\
(\mathrm{HL})^{* *}\end{array}$ & $\begin{array}{l}\text { No. of } \\
\text { strains }\end{array}$ & $\begin{array}{c}\text { Frequency } \\
(\%)\end{array}$ \\
\hline 13 & 8 & $7 \cdot 6$ & 21 & 26 & $24 \cdot 8$ \\
\hline 21 & 8 & $7 \cdot 6$ & 2 & 17 & $16 \cdot 2$ \\
\hline 5 & 7 & $6 \cdot 7$ & 9 & 17 & $16 \cdot 2 *$ \\
\hline 8 & 6 & $5 \cdot 7$ & 4 & 13 & $12 \cdot 4$ \\
\hline 1 & 6 & $5 \cdot 7$ & 36 & 10 & $9 \cdot 5$ \\
\hline 11 & 5 & $4 \cdot 8$ & 11 & 8 & $7 \cdot 6$ \\
\hline 4 & 4 & $3 \cdot 8$ & 20 & 1 & $7 \cdot 6$ \\
\hline 2 & 4 & $3 \cdot 8$ & 13 & 1 & 0.95 \\
\hline 14 & 4 & $3 \cdot 8$ & 17 & 1 & 0.95 \\
\hline 9 & 3 & $2 \cdot 9$ & 8 & 1 & 0.95 \\
\hline 37 & 3 & $2 \cdot 9$ & - & - & - \\
\hline 23 & 3 & $2 \cdot 9$ & - & - & - \\
\hline 16 & 3 & $2 \cdot 9$ & - & - & - \\
\hline 15 & 2 & 1.9 & - & - & - \\
\hline 25 & 2 & 1.9 & - & - & - \\
\hline 3 & 2 & 1.9 & - & - & - \\
\hline 6 & 1 & 0.95 & - & - & - \\
\hline 17 & 1 & 0.95 & - & - & - \\
\hline 18 & 1 & 0.95 & - & - & - \\
\hline 22 & 1 & 0.95 & - & - & - \\
\hline 10 & 1 & 0.95 & $\ldots$ & - & - \\
\hline 19 & 0 & $0 \cdot 0$ & - & - & - \\
\hline 20 & 0 & $0 \cdot 0$ & & & - \\
\hline Total typable & 75 & $71 \cdot 4$ & - & 95 & $90 \cdot 5$ \\
\hline Not typable & 30 & $28 \cdot 6$ & & 10 & 9.5 \\
\hline
\end{tabular}

When the strains isolated from Mexican patients with symptoms were compared to those from patients with no symptoms, the same HS antigens and HL antigens could with few exceptions be identified in the two groups (Tables 2,3 ). The HS antigen, serotype 37 , was significantly $(P<0.05)$ more common in the symptomatic group (Table 2) while the HL antigen, serotype $9(P<0.05)$ was more common among the asymptomatic children (Table 3 ).

In the Swedish patients with symptoms serotypes $2(P<0.05), 1$ and 4 , were the most frequently identified, HS-antigens; in the Mexican patients with or without symptoms serotypes $1,8,5,13$, and 21 were the most common. The HL-antigens $4(P<0.05), 2$ and 1 were most commonly found in the Swedish group and HLantigens $21(P<0.001), 2$ and 9 in the Mexican group.

\section{DISCUSSION}

The importance of $C$. jejuni as a cause of sporadic and epidemic outbreaks (Jones et al. 1981 ; Riley \& Finch, 1985; Skirrow, 1987), as well as for travellers' 


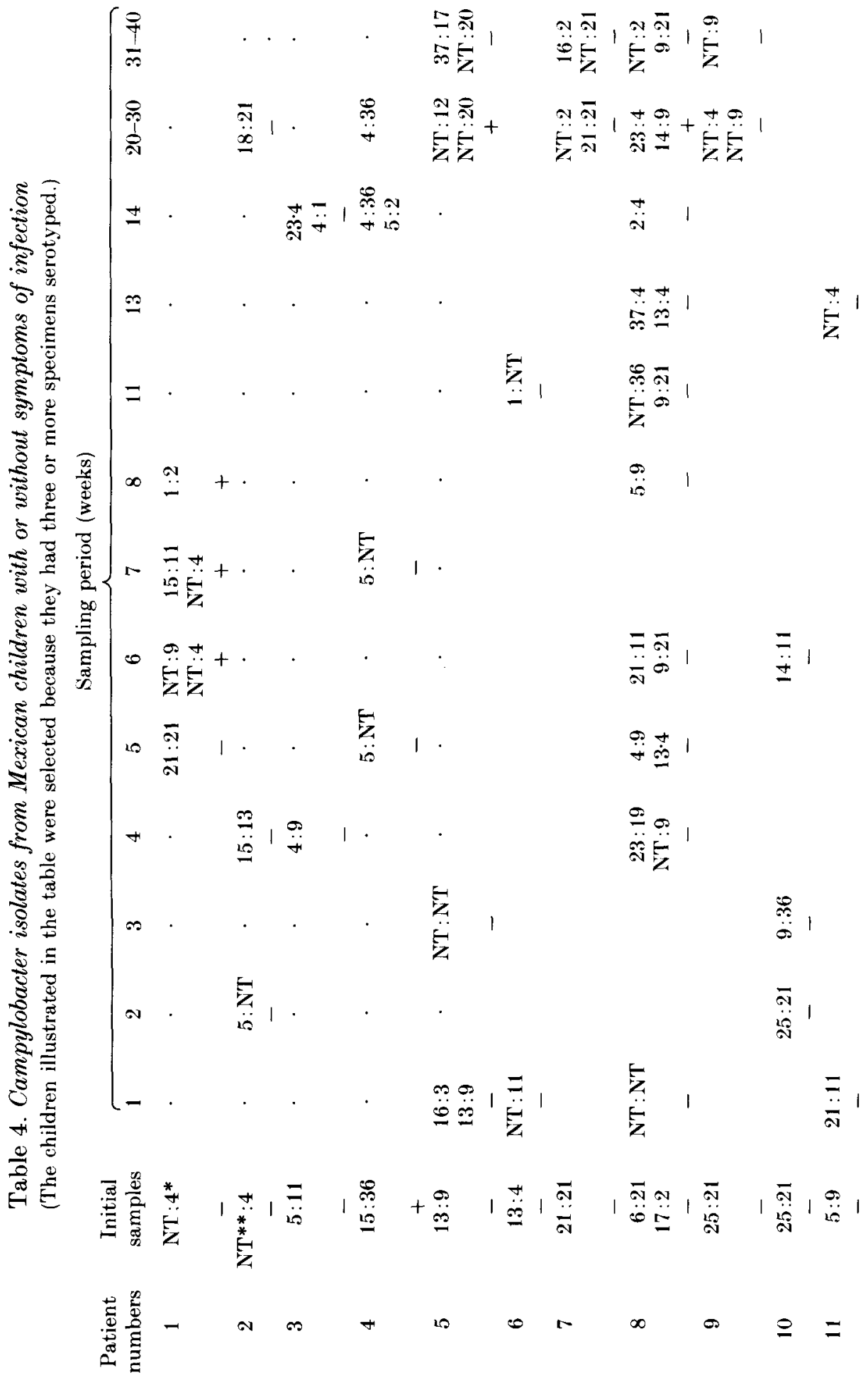



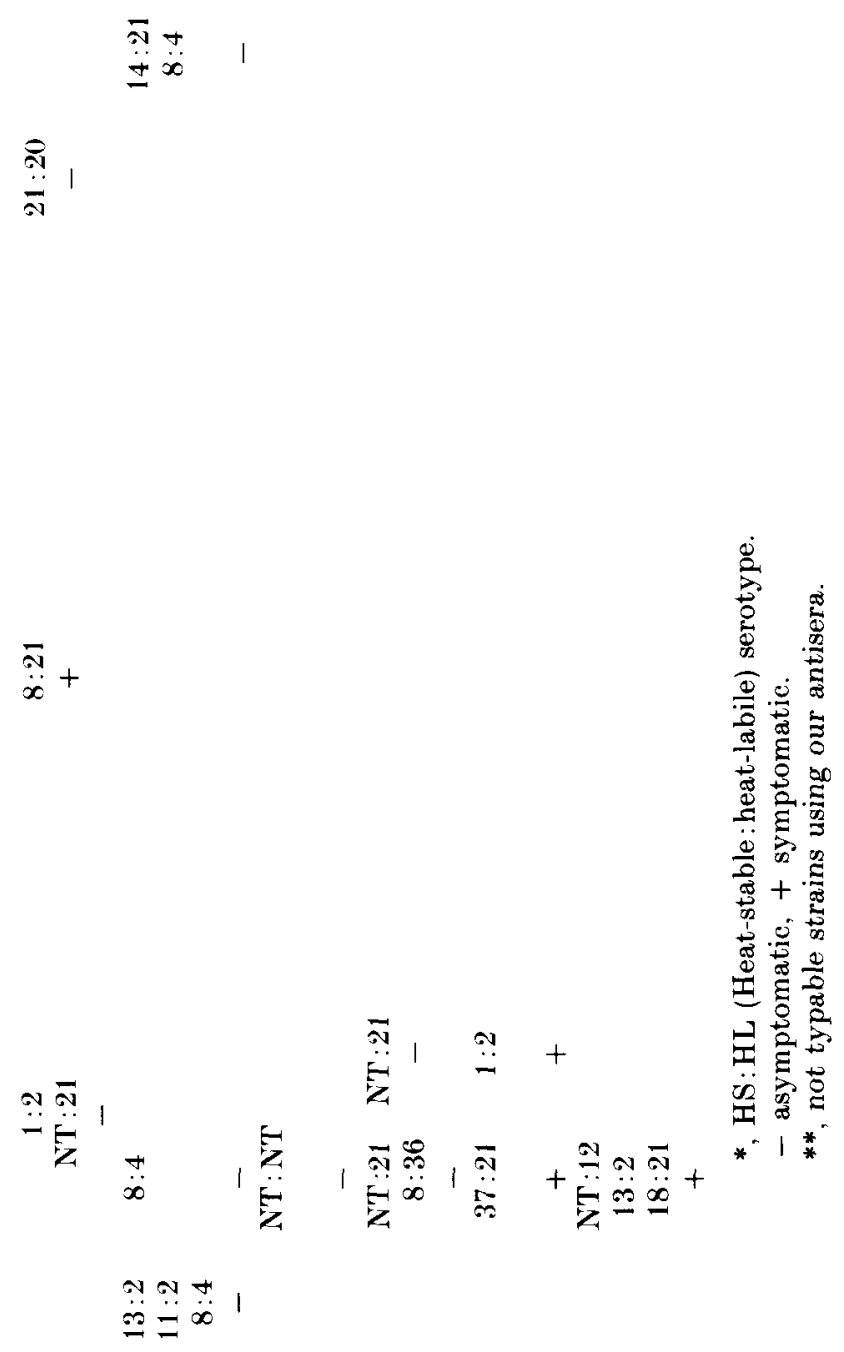

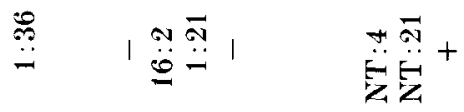

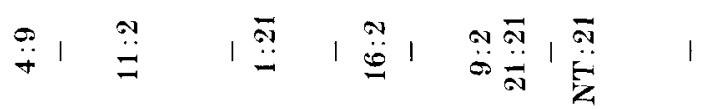

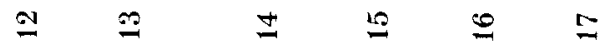


diarrhoea (Ryder et al. 1981 ; Speelman, 1983; Jertborn, 1988), is nowadays well established.

By serotyping strains originating from Mexican and Swedish patients, and identifying both the HS and the HL antigen, it was shown that both the frequency of colonization and the number of strains colonizing the patients in the two groups were different. Most of the Mexican children had three or more episodes during the study-year and one child was infected as many as 11 times with different campylobacter isolates during the study. Out of the 62 patients, $41.9 \%$ were also infected with mixed Campylobacter sp. at the same time of isolation, which was confirmed by serotyping morphologically different colonies from the same sample. This is in agreement with the study by Lastovica et al. (1986) where different campylobacter colonies from the primary isolation media were shown to be of different strains. The illness-to-infection ratio among the children decreased with increasing age, which was in accordance with other investigations (Glass et al. 1983; Calva et al. 1988; Taylor et al. 1988; Blaser et al. 1986). The study of Calva et al. shows that children at the age of 12-17 months had a diarrhoea-episode peak with 3.5 episodes/child/year. Glass et al. (1983) postulated an incidence rate for children living in Bangladesh of approximately 8.2 infections per child per year during the first 5 years of life.

The Swedish patients, on the other hand, with very few exceptions, were infected with one strain each time and reinfections were very rare. This pattern was found regardless of whether the patient was infected in Sweden or abroad.

The repeated infection episodes among the Mexican children, as a result of massive exposure is probably responsible for the high frequency of asymptomatic cases $(P<0 \cdot 001)$, as opposed to episodes associated with diarrhoea. This interpretation is in agreement with the longitudinal study from Calva et al., where the illness-to-infection ratio was investigated in the same group of children. They concluded that symptom-producing early campylobacter infections seemed to protect against subsequent infection, whereas symptom-free infections do not (Calva et al. 1988). Asymptomatic episodes are less common or rare among people living in industrialized countries.

Comparing the serotypes common in Sweden with those common in Mexico, we found that for both HS and HL antigens, despite the wide serologic heterogeneity of $C$. jejuni, most clinical isolates belonged to relatively few serotypes. Similar findings have previously been reported from our own studies (Kaijser \& Sjögren, 1985) as well as those of others (Patton et al. 1985).

Antigens (HS and HL) identified on strains from Mexican patients with symptomatic infections were, with few exceptions, the same as those isolated from patients without symptoms. HS-antigen serotype 37 was significantly $(P<0.05)$ more common in symptomatic groups, and the HL-antigen serotype $9(P<0.05)$ was more common in the asymptomatic group.

Several epidemiological studies have indicated that immunity against $C . j e j u n i$ in humans is induced as a consequence of one or more infections (Glass et al. 1983; Calva et al. 1988; Jones et al. 1981). Blaser et al. (1983) have shown that persons who drink raw milk regularly and presumably have multiple exposures to $C$. jejuni, and have persistent elevations in anti-campylobacter immunoglobulin $\mathrm{G}$ levels. They show little or no campylobacter-related symptoms compared to 
persons who drink raw milk for the first time. From these data the authors suggested that repeated exposure may lead to the acquisition of immunity. Svedhem et al. (1983) found that chicken slaughterhouse workers have an increased incidence of campylobacter antibody in serum as a consequence of daily exposure to eampylobacter antigen. The workers reported that after an initial working-period with frequent diarrhoea episodes, they seldom fell ill with enterocolitis symptoms (personal communication). From the study of Calva $e t$ al., there was a marked decrease in the illness-to-infection ratio with increasing age. Infants under 6 months of age had a ratio of $1: 1$, while infected children over 5 years of age did not have diarrhoea at all (Calva et al. 1988). In our present study on the Mexican children the finding of new serotypes in every reinfection might be compatible with a theory of induced immunity to surface antigen(s).

Several animal experimental studies have indicated the existence of homologous protective immunity by demonstrating the development of specific antibody responses to campylobacter infection (Ruiz-Palacios et al. 1983; Fitzgeorge et al. 1981 ; Burr et al. 1988).

Furthermore in studies among volunteers in the United States, Black et al. (1985) showed a natural immunity after repeated infections with Campylobacter sp. The study indicated the existence of a short-term homologous, protective immunity.

In conclusion we found that Swedish patients, who were mostly symptomatic, in general were infected with only one serotype of campylobacter and were rarely infected. Mexican patients, on the other hand, were in general infected with several serotypes and moreover were frequently reinfected with new, different serotypes. These results are in concordance with the development of an induced immunity to $C$. jejuni infection.

The investigation was supported by grants from the Swedish Council for Forestry and Agricultural Research grant No. 598, Swedish Medical Research Council grant No. 07169 and National Council for Science and Technology (CONDCYT, Mexico) grant No. PcSDBND-021739 and National Institutes of Health (NIH, USA) grant No. 5293. The skilful typing of manuscripts by Ms Anne-Bell Ek was much appreciated.

\section{REFERENCES}

Alabi. S. A., Coker, A. O., Doscmmi-Ogenbi, O. \& Odcgaemi, T. (1986). Biotype and serogroup distribution of Campylobacter isolates from children in Nigeria. Journal of Clinical Microbiology 24, 856-858.

Black. R. E., I,evine, M. M., Brown, K. H. Clements, M. L. \& Lopez de Romana, G. (1985). Immunity to Campylobacter jejuni in man. In Campylobacter III (ed. A. D. Pearson, M. B. Skirrow, H. Lior and B. Rowe), London: Public Health Laboratory Service.

Blaser, M. J., Duncan, D. J., Ostermalm, M. T., Istre, G. R. \& Wang, W. L. (1983) Serologic study of two clusters of infection due to Campylobacter jejuni. Journal of Infectious Diseases 147, 820-823.

Blaser, M. J., Perez-Perez, G., Smith, P. F., Patton, C., Tenover, F. C., Lastovica, A. J. \& WANG, W.-L. L. (1986). Extraintestinal Campylobacter jejuni and Campylobacter coli infections : host factor and strain characteristics. Journal of Infectious Diseases 153, 552-559.

Blaser, M. J., Taylor, D. N. \& Echeverria, P. (1986). Immune response to Campylobacter jejuni in a rural community in Thailand. Journal of Infectious Diseases 153, 249-254. 
Burr, D. H., Caldwell, M. B., Bourgeois, A. L., Morgan, H. R., Wistar Jr, R. \& Walker, R. I. (1988). Mucosal and systemic immunity to Campylobacter jejuni in rabbits after gastric inoculation. Infection and Immunity 56, 99-105.

Calva, J. J., Ruiz-Palacios, G. M., Lopez-Vidal, A. B., Ramos, A. \& Bojalil, R. (1988). Cohort study of intestinal infection with campylobacter in Mexican children. Lancet $\mathbf{I}$, 503-506.

Colton, T. (1974). Statistics in Medicine Boston, Massachusetts : Little, Brown and Company. Fitzg eorge, R. B., Baskerville, A. \& Lander, K. P. (1981). Experimental infection of rhesus monkeys with a human strain of Campylobacter jejuni. Journal of Hygiene 86, 343-351.

Georges-Courbot, M. C., Baya, C., Beraud, A. M., Meunier, D. M. Y. \& Georges, A. J. (1986). Distribution and serotypes of Campylobacter jejuni and Campylobacter coli in enteric Campylobacter strains isolated from children in the Central African Republic. Journal of Clinical Microbiology 23, 592-594.

Grass, R. I., Stoll, B. J., Huq, M. I., Struelens, M. J., Blaser, M. \& Kibriya, A. K. M. G. (1983). Epidemiologic and clinical features of endemic Campylobacter jejuni infection in Bangladesh. Journal of Infectious Diseases 148, 292-296.

Guerrant, R. L., Lahita, R. G., Winn JR, W. C. \& Roberts, R. B. (1978). Campylobacteriosis in man: pathogenic mechanisms and review of 91 bloodstream infections. American Journal of Medicine 65, 584-592.

Guerrant, R. L., Wanke, C. A., Pennie, R. A., Barrett, L. J., Lima, A. A. M. \& O'Brien, A. D. (1987). Production of a unique cytotoxin by Campylobacter jejuni. Infection and Immunity 55, 2526-2530.

Jertborn, M., Svennerholm, A.-M. \& Iwarson, S. (1988). A prospective study of serum antibody responses to enterotoxigenic Escherichia coli in Swedish travellers. Scandinavian Journal of Infectious Diseases 20, 69-75.

Johnson, W. M. \& Lior, H. (1986). Cytotoxic and cytotonic factors produced by Campylobacter jejuni, Campylobacter coli and Campylobacter laridis. Journal of Clinical Microbiology 24, $275-281$.

Jones, D. M., Robinson, D. A., \& Eldridge, J. (1981). Serological studies in two outbreaks of Campylobacter jejuni infection. Journal of Hygiene 87, 163.

Jones, P. H., Willis, A. T., Robinson, D. A., Skirrow, M. B. \& Josephs, D. S. (1981). Campylobacter enteritis associated with consumption of free school milk. Journal of Hygiene $87155-162$.

KaiJser, B. \& Sjögren, E. (1985). Campylobacter strains in Sweden. Serotyping and correlation to clinical symptoms. Acta Pathologica et Microbiologica Scandinavica 93, 315-322.

Karmali, M. A., Penner, J. L., Flemming, P. C., Williams, A. \& Hennessy, J. N. (1983). The serotype and biotype distribution of clinical isolates of Campylobacter jejuni and Campylobacter coli over a three-year period. Journal of Infectious Diseases 147, 243-245

Klipstein, F. A. \& Engert, R. F. (1984). Properties of crude Campylobacter jejuni heat-labile enterotoxin. Infection and Immunity 45, 314-319.

Klipstein, F. A., Engert, R. F., Short, H. \& Schenk, E. A. (1985). Pathogenic properties of Campylobacter jejuni: assay and correlation with clinical manifestations. Infection and Immunity 50, 43-49.

Lastovica, A. J., Le Roux, E. \& Penner, J. L. (1986). Mixed infections with different species and serotypes of Campylobacter. Journal of Infectious Diseases 154, 375.

Lior, H., Woodward, D. I., Edgar, J. A., Laroche, I. J. \& Gill, P. (1982). Serotyping of Campylobacter jejuni by slide agglutination based on heat-labile antigenic factors. Journal of Clinical Microbiology 15, 761-768.

Mathan, V.J., Rajan, D. P., Klipstein, F. A. \& Engert, R. F. (1984). Prevalence of enterotoxigenic Campylobacter jejuni among children in South India. Lancet ii, 981.

MCSWEEgaN, E. \& WALKER, R. I. (1986). Identification and characterization of two Campylobacter jejuni adhesins for cellular and mucous substrates. Infection and Immunity 53, 141-148.

New Ell, D. G. \& MCBride, H. (1985). Investigations on the role flagella in colonization of infant mice with Campylobacter jejuni and attachment of Campylobacter jejuni to human epithelial cell lines. Journal of Hygiene 95, 217-227.

Patton, C. H., Barretr, T. J. \& Morris, G. K. (1985). Comparison of the Penner and Lior methods for serotyping Campylobacter spp. Journal of Clinical Microbiology 22, 558-565. 
Penner, J. L., Hennessy, J. N. \& Congi, R. V. (1983). Serotyping of Campylobacter jejuni and Campylobacter coli on the basis of thermostable antigen. European Journal of Clinical Microbiology 2, 378-383.

Pennie, R. A., Pearson, R. D., Barrett, L. J., Lior, H. \& Guerrant, R. L. (1986). Susceptibility of Campylobacter jejuni to strain-specific bactericidal activity in sera of infected patients. Infection and Immunity 52, 702-706.

Riley, L. W. \& Finch, M. J. (1985). The result of the first year of National Surveillance of Campylobacter infections in the United States. Journal of Infectious Diseases 151, 956-959.

Ruiz-Palacios, G. M., Lopez-Vidal, Y., Lopez-Vidal, A. B., Torres, J. \& Rubino, S. (1983). Systemic and local immune response in experimental campylobacter infection. In Campylobacter II. (Eds. A. D. Pearson, M. B. Skirrow, B. Rowe, J. R. Davies \& D. M. Jones), pp. 115-116. London: Health Laboratory Service.

Ryder, R. W., Oquist, C. A., Greenberg, H., Taylor, D. N., Ørskov, F., Ørskov, I., Kapikian, A. Z. \& SACK, R. B. (1981). Travellers' diarrhoea in Panamanian tourists in Mexico. Journal of Infectious Diseases 144, 442-448.

Sjögren, E., Lindblom, G.-B. \& Kaijser, B. (1987). Comparison of different procedures, transport media and enrichment media for isolation of Campylobacter species from healthy laying hens and humans with diarrhea. Journal of Clinical Microbiology 25, 1966-1968.

Skirrow, M. B. (1977). Campylobacter enteritis: a 'new' disease. British Medical Journal, ii, $9-11$.

SkIRrow, M. B. (1987). A demographic survey of campylobacter, salmonella and shigella infections in England. Epidemiology and Infection 99, 647-657.

Speelman, P., Struelens, M. J., Sanyal, S. C. \& Glass, R. I. (1983). Detection of Campylobacter jejuni and other potential pathogens in travellers' diarrhoea in Bangladesh. Scandinavian Journal of Gastroenterology 18, (Suppl 84), 19-23.

Svedhem, A. \& KaIJSer, B. (1980). Campylobacter fetus subspecies jejuni: common cause of diarrhea in Sweden. Journal of Infectious Diseases 142, 353-359.

Taylor, D. N., Echeverria, P., Pitarangsi, C., Seriwatana, J., Bodhidatta, L. \& Blaser, M. (1988). Influence of strain characteristics and immunity on the epidemiology of campylobacter infections in Thailand. Journal of Clinical Microbiology 26, 863-868. 